\title{
Knowledge, Attitude and Practices Regarding Biomedical Waste Management as Per 2019 Rules among Nursing Students
}

\author{
Surya Kant Tiwari ${ }^{1}$, Saumya P. Srivastava ${ }^{2}$, Soni Chauhan ${ }^{3}$ \\ ${ }^{1}$ Lecturer, Yatharth Nursing College and Paramedical Institute, Chandauli, U.P. \\ ${ }^{2}$ Lecturer, Vivekananda College of Nursing, Lucknow, U.P. \\ ${ }^{3}$ Lecturer, Yatharth Nursing College and Paramedical Institute, Chandauli, U.P.
}

Corresponding Author: Soni Chauhan

\begin{abstract}
Introduction- Biomedical waste is of global subject today. The biomedical waste (management and handling) rules came into existence in 1998 with the latest amendment being made in 2019.

Methods- This descriptive cross-sectional study was carried among 163 nursing students to assess the knowledge, attitude, and practices regarding biomedical waste management as per 2019 rules using total enumeration method. Nursing students who had clinical exposure $\geq 6$ months and willing to participate were included in the study. Nursing students who were in their $1^{\text {st }}$ academic year were excluded. The questionnaire was divided into four components assessing knowledge, attitude, and practices regarding biomedical waste management. The obtained scores of participants were converted into percentages and categorized as excellent $(\geq 70 \%)$ and poor $(<70 \%)$.

Results- Mean age of participants was $21.54 \pm 2.49$ years with the majority being female $(81.6 \%)$ and studying in B.Sc. nursing (59.5\%). Majority of participants had poor level of knowledge in various domains of biomedical waste management like awareness (78.5\%), color coding (84.7\%), biomedical waste disposal methods (92.6\%), and universal precautions (97.5\%) except for biomedical waste hazard symbol (15.3\%). About $95.1 \%$ of participants had overall poor knowledge regarding biomedical waste management. Nearly $76.1 \%$ and $74.2 \%$ of participants showed positive attitudes and safe practice patterns respectively.

Conclusion- Although nursing student's attitudes and patterns of practice were excellent yet they had an unsatisfactory level of knowledge related to recent amendments in biomedical waste management rules, 2019. Regular teaching and periodic monitoring of practices regarding biomedical waste are highly recommended.
\end{abstract}

Keywords- knowledge, attitude, practices, biomedical waste, nursing students

\section{INTRODUCTION}

"Biomedical waste is waste generated during diagnosis, treatment, or immunization of human beings or animals, or in research activities pertaining thereto, or in the production and testing of biological and is contaminated with human fluids". ${ }^{[1}$ The majority (75-90\%) of the health caregenerated wastes are general waste or having no risk as such and the remaining are hazardous wastes. ${ }^{[2]}$ Rapid population growth and increased demand for health care have significantly increased health care institutions. ${ }^{[3]}$ Ironically, hospitals that are centers for care and treatment are also possessing threat to patient's health and safety ${ }^{[4]}$ by generating a significant amount of biomedical waste.

The biomedical waste (management and handling) rules came into existence in 1998 and subsequent amendments have been made in 2000, 2003, 2016, 2018, and 
2019. [5] As per the latest amendments, centers of biomedical waste generation such as hospitals will not use chlorinated plastic bags and gloves in medical applications to save the environment. [6] Recent amendments have made bar code systems mandatory for proper control of biomedical waste. It has also increased coverage to include healthcare waste produced at home. [7]

Biomedical waste is of global subject today. Inadequate and insufficient knowledge, attitude, and practices concerning biomedical waste control have excessive potential for injury and contamination to self in addition to others and can additionally have severe environmental consequences. ${ }^{[7,8]}$ There are strong shreds of evidence to show transmission of life-threatening diseases such as HIV/AIDS, Hepatitis B, and C through improper biomedical waste management.

Developed countries have reported increased awareness while developing counties such as India, have reported poor knowledge, attitude, and practices regarding biomedical waste management among health care workers. ${ }^{[7,10-12]}$ It is not only legal but also social responsibility of every health care professional to ensure proper disposal of health care generated waste on their part. Some research evidence suggests that knowledge regarding biomedical waste management among students is not appropriate. ${ }^{[13]}$

Teaching institutions with attached hospitals have an important duty towards society to train nursing students such that they can manage biomedical wastes efficiently. Practices during early careers remain permanent and do not change easily. Nursing students need to be equipped with good knowledge, attitude, and practices regarding recent amendments and advancements to ensure optimal compliance with biomedical waste management rules. Most of the studies are carried out among health care workers but to the best of author's knowledge, there are no such studies which have assessed gaps in knowledge, attitude, and practices concerning biomedical waste management rule 2019 amongst nursing students. Hence the present study was undertaken with the objective to assess the knowledge, attitude, and gaps in the practices regarding the biomedical waste management rule 2019, so that future teaching and skill training can be arranged for the students.

\section{MATERIAL AND METHODS}

The present non-experimental descriptive cross-sectional study was carried out at two private nursing colleges to assess knowledge, attitude, and practices level among nursing students in the first week of June 2021 using total enumeration method. Necessary permissions were obtained from the concerned authority. Objectives of the study were clearly mentioned and participants were given option to withdraw from the study if appropriate. All participants were assured about the confidentiality and anonymity of the obtained information.

Considering the prevalence of knowledge about biomedical waste management rules as $10 \%{ }^{[14]}$ in nursing students at $95 \%$ Confidence Interval with $5 \%$ precision, the sample size was calculated to be 141 . The inclusion criteria included the nursing students who had clinical exposure of $\geq 6$ months and willing to participate in the study. Nursing students who were in their $1^{\text {st }}$ academic year were excluded from the study. All nursing students who fulfilled inclusion criteria were invited through WhatsApp and mail to participate in the study. A total of 163 nursing students participated in the present study. After an extensive review of literature and consultation with subject experts, a structured online selfadministered knowledge, attitude, and practices questionnaire was developed using web-based Google forms with attached information sheet and instructions, which went through the process of content and 
face validity by experts. The questionnaire was divided into four components.

Part I comprised of sociodemographic proforma which included age, gender, educational qualifications, type of residence, marital status, type of family, and family income per month. Part II contained 20 multiple-type questions covering five dimensions of knowledge related to biomedical waste management namely awareness, color coding, biomedical waste disposal methods, universal precautions, and biomedical waste hazard symbol. Part III included 10 attitude-related questions on Likert scale (Agree, Ascertain, Disagree) assessing both positive and negative attitudes regarding biomedical waste management. Part IV comprised of 10 questions related to practices among nursing students about biomedical waste management in positive or negative response format (Yes/No).

Each participant was given one score for each correct answer and zero scores for each wrong answer in knowledge and practices components of the tool while for positive attitude, a score of two was given for agree, one for ascertain and zero for disagree, and for the negative attitude, a score of two was given for disagree, one for ascertain and zero for agree, thus maximum possible scores of each participant for knowledge, attitude and practices were 20 , 20 and 10 respectively. Considering the criticality of biomedical waste hazards, the obtained knowledge, attitude, and practices scores of participants were converted into percentages and categorized as excellent $(\geq$ $70 \%)$ and poor $(<70 \%)$.

\section{Statistical analysis}

The collected data were coded and then summarized in master data sheet using Microsoft Excel spreadsheet. Data analysis was done by statistical program SPSS 20.0 version using both descriptive and inferential statistics. Frequency, percentage, mean, standard deviation, and range were calculated in descriptive statistics. Chisquare test was used to find out the association between knowledge and practice levels among nursing students. The level of significance was set at $\mathrm{p}$-value $<0.05$.

\section{RESULT}

A total of 163 nursing students participated in the study. Mean age of participants was $21.54 \pm 2.49$ years with the majority being female $(81.6 \%)$ and studying in B.Sc. nursing (59.5\%). About half of the participants belonged to nuclear families (52.8\%) and having a family monthly income of Rs. < 10,000 (47.9\%) (Table 1)

\begin{tabular}{|l|l|}
\hline \multicolumn{2}{|l|}{$\begin{array}{l}\text { Table 1: Socio-demographic characteristics of participants } \\
\text { (N=163) }\end{array}$} \\
\hline & Frequency (\%) \\
\hline Age (years) & $21.54 \pm 2.49(18-32)$ \\
Mean \pm SD (Range) & \\
\hline Gender & $30(18.4)$ \\
Male & $133(81.6)$ \\
Female & $52(31.9)$ \\
\hline Course & $6(3.7)$ \\
GNM & $97(59.5)$ \\
P.B. B.Sc. (N) & $8(4.9)$ \\
B.Sc. (N) & \\
M.Sc. (N) & $115(70.6)$ \\
\hline Type of residence & $48(29.4)$ \\
Rural & $13(8.0)$ \\
Urban & $150(92.0)$ \\
\hline Marital status & \\
Married & $86(52.8)$ \\
Unmarried & $77(47.2)$ \\
\hline Type of family & \\
Nuclear & $78(47.9)$ \\
Joint & $69(42.3)$ \\
\hline Family income (per month) & $13(8.0)$ \\
Rs. < 10,000 & $3(1.8)$ \\
Rs. 10,000 - 40,000 & \\
Rs. 40,000 - 1,20,000 & \\
above Rs 1,20,000 &
\end{tabular}

\begin{tabular}{|c|c|c|}
\hline \multirow{2}{*}{ Domain (items) } & \multicolumn{2}{|c|}{ Knowledge, Frequency (\%) } \\
\hline & Excellent & Poor \\
\hline Awareness (2) & $35(21.50)$ & $128(78.5)$ \\
\hline Colour coding $(6)$ & $25(15.3)$ & $138(84.7)$ \\
\hline $\begin{array}{lll}\begin{array}{l}\text { Biomedical } \\
\text { methods (6) }\end{array} & \text { waste } & \text { disposal } \\
\end{array}$ & $12(7.4)$ & $151(92.6)$ \\
\hline Universal precautions (5) & $4(2.5)$ & $159(97.5)$ \\
\hline Biomedical symbol (1) & $138(84.7)$ & $25(15.3)$ \\
\hline
\end{tabular}

Table 2 illustrates domain-wise knowledge related to biomedical waste management among study participants. Unfortunately, the majority of participants had poor level of knowledge in various domains of biomedical waste management like awareness (78.5\%), color coding $(84.7 \%)$, biomedical waste disposal methods $(92.6 \%)$, and universal precautions $(97.5 \%)$ 
Surya Kant Tiwari et.al. Knowledge, attitude and practices regarding biomedical waste management as per 2019 rules among nursing students.

except for biomedical hazard symbol $(15.3 \%)$.

Table 3 clearly explains the attitude of nursing students regarding biomedical waste management. Majority $(93.3 \%$, $91.4 \%$, and $93.9 \%$ ) of participants agreed that color-coding system is a simple method for segregating biomedical waste, wearing gloves is necessary to prevent medical waste hazards, and always putting waste in correct plastic bag respectively. About two-third $(62 \%$ and $62.6 \%)$ participants agreed that biomedical waste can harm the health of the public at large, and all waste generated in hospital are infectious respectively. More than two in three participants disagreed that biomedical waste is an extra burden on their work $(69.3 \%)$ and wearing PPE increases the risk of infection (68.7\%). About $87.7 \%$ were willing to attend an educational program on biomedical management.

\begin{tabular}{|l|l|l|l|}
\hline \multicolumn{3}{|l|}{ Table 3: Attitude regarding biomedical waste management } \\
among participants, (N=163)
\end{tabular}

Table 4 depicts practices regarding biomedical waste management among participants. About $85.9 \%$ of participants segregate waste at their generation point.
Majority of participants ensure tying up the waste bag when it is $3 / 4^{\text {th }}$ filled $(76.7 \%)$, a practice of not recapping the used needles $(60.7 \%)$, dispose-off biomedical waste in the specified color-coded container $(96.3 \%)$, discard used needles in needle destroyer $(88.3 \%)$, record and report needlestick and sharps injury $(84.0 \%)$ and change gloves between patients $(81.6 \%)$. Only $66.9 \%$ and $81.6 \%$ of participants were vaccinated against Hepatitis B and TT respectively. Sadly, $60.7 \%$ had previous exposure to needle stick or sharps injury.

\begin{tabular}{|l|l|l|}
\hline \multicolumn{2}{|l|}{$\begin{array}{l}\text { Table 4: Practices regarding biomedical waste management } \\
\text { among participants, (N=163) }\end{array}$} & \multicolumn{2}{|l|}{ Practices, Frequency (\%) } \\
\cline { 2 - 3 } & Yes & No \\
\hline $\begin{array}{l}\text { Segregate waste at the point of } \\
\text { generation }\end{array}$ & $140(85.9)$ & $23(14.1)$ \\
\hline $\begin{array}{l}\text { Ensure tying up the waste bag when } \\
\text { it is 3/4 } 4^{\text {th }} \text { filled }\end{array}$ & $125(76.7)$ & $38(23.3)$ \\
\hline $\begin{array}{l}\text { Practice not recapping the used } \\
\text { needles }\end{array}$ & $99(60.7)$ & $64(39.3)$ \\
\hline $\begin{array}{l}\text { Dispose-off biomedical waste in the } \\
\text { specified color-coded container }\end{array}$ & $157(96.3)$ & $6(3.7)$ \\
\hline $\begin{array}{l}\text { Discard used needles in needle } \\
\text { destroyer }\end{array}$ & $144(88.3)$ & $19(11.7)$ \\
\hline $\begin{array}{l}\text { Record and report needlestick and } \\
\text { sharps injury }\end{array}$ & $137(84.0)$ & $26(16.0)$ \\
\hline $\begin{array}{l}\text { Have you taken vaccination against } \\
\text { Hepatitis B? }\end{array}$ & $109(66.9)$ & $54(33.1)$ \\
\hline $\begin{array}{l}\text { Have you taken vaccination against } \\
\text { TT? }\end{array}$ & $133(81.6)$ & $30(18.4)$ \\
\hline $\begin{array}{l}\text { Previous exposure to needle stick or } \\
\text { sharps injury? }\end{array}$ & $99(60.7)$ & $64(39.3)$ \\
\hline Change gloves between patients & $133(81.6)$ & $30(18.4)$ \\
\hline
\end{tabular}

Table 5 shows that mean scores \pm SD of knowledge, attitude and practices was $9.52 \pm 2.49,15.66 \pm 2.69$ and $7.83+1.85$ respectively. Overall knowledge of participants was poor for $155(95.1 \%)$ while $124(76.1 \%)$ and $121(74.2 \%)$ participants were having excellent overall attitudes and practices respectively.

\begin{tabular}{l}
\hline $\begin{array}{l}\text { Table 5: Overall knowledge, attitude, and practices related to } \\
\text { biomedical waste management among } \\
\text { (N=163) }\end{array}$ \\
\hline \\
\hline
\end{tabular}

Table 6 illustrates that there is no statistically significant association between sociodemographic variables and knowledge levels concerning biomedical waste management. 
Surya Kant Tiwari et.al. Knowledge, attitude and practices regarding biomedical waste management as per 2019 rules among nursing students.

\begin{tabular}{|c|c|c|c|c|c|}
\hline \multirow{2}{*}{ Sociodemographic variables } & \multicolumn{2}{|c|}{ Knowledge level } & \multirow{2}{*}{ Chi-square value } & \multirow[t]{2}{*}{$d f$} & \multirow[t]{2}{*}{$p$-value } \\
\hline & $\begin{array}{l}\text { Excellent } \\
n(\%)\end{array}$ & $\begin{array}{l}\text { Poor } \\
n(\%)\end{array}$ & & & \\
\hline $\begin{array}{l}\text { Gender } \\
\text { Male } \\
\text { Female } \\
\end{array}$ & $\begin{array}{l}7(87.5) \\
1(12.5) \\
\end{array}$ & $\begin{array}{l}126(81.6) \\
30(18.4) \\
\end{array}$ & 0.195 & 1 & $0.659^{\mathrm{NS}}$ \\
\hline $\begin{array}{l}\text { Course } \\
\text { GNM } \\
\text { P.B. B.Sc. (N) } \\
\text { B.Sc. (N) } \\
\text { M.Sc. (N) }\end{array}$ & $\begin{array}{l}0(0) \\
1(12.5) \\
7(87.5) \\
0(0)\end{array}$ & $\begin{array}{l}52(33.5) \\
5(3.2) \\
90(58.1) \\
8(5.2)\end{array}$ & 5.982 & 3 & $0.112^{\mathrm{NS}}$ \\
\hline $\begin{array}{l}\text { Type of residence } \\
\text { Rural } \\
\text { Urban }\end{array}$ & $\begin{array}{l}6(75.0) \\
2(25.0)\end{array}$ & $\begin{array}{l}109(70.3) \\
46(29.7)\end{array}$ & 0.80 & 1 & $0.777^{\mathrm{NS}}$ \\
\hline $\begin{array}{l}\text { Marital status } \\
\text { Married } \\
\text { Unmarried }\end{array}$ & $\begin{array}{l}1(12.5) \\
7(87.5)\end{array}$ & $\begin{array}{l}12(7.7) \\
143(92.3)\end{array}$ & 0.235 & 1 & $0.628^{\mathrm{NS}}$ \\
\hline $\begin{array}{l}\text { Type of family } \\
\text { Nuclear } \\
\text { Joint }\end{array}$ & $\begin{array}{l}3(37.5) \\
5(62.5)\end{array}$ & $\begin{array}{l}83(53.5) \\
72(46.5)\end{array}$ & 0.786 & 1 & $0.375^{\mathrm{NS}}$ \\
\hline $\begin{array}{l}\text { Family income (per month) } \\
\text { Rs. }<10,000 \\
\text { Rs. } 10,000-40,000 \\
\text { Rs. } 40,000-1,20,000 \\
\text { above Rs } 1,20,000\end{array}$ & $\begin{array}{l}4(50) \\
3(37.5) \\
1(12.5) \\
0(0)\end{array}$ & $\begin{array}{l}74(47.7) \\
66(42.6) \\
12(7.7) \\
3(1.9)\end{array}$ & 0.425 & 3 & $0.935^{\mathrm{NS}}$ \\
\hline
\end{tabular}

\section{DISCUSSION}

An appropriate knowledge, positive attitude, and good level of practice are crucial factors for proper biomedical wastes management. The present study uncovered that the level of knowledge regarding recent amendments in biomedical waste management rules, 2019 among nursing students was poor yet they reflected positive attitudes and good practice patterns. Health care providers are at the frontline in the management of biomedical waste and inadequate knowledge and improper practices among them would be a potential threat to not only to themselves as wells as for others also.

Only a few studies carried out knowledge, attitude, and practices regarding recent amendments in biomedical waste management rules among nursing/medical students and health care providers. The present study was carried out among nursing students only. In our study, there was highly unsatisfactory level of knowledge with nearly $95.1 \%$ of participants falling in the poor knowledge category, which is exceedingly more when compared to several studies conducted among nurses. $[13,15,16]$ Other studies showed poor knowledge levels among nursing students when compared to medical students regarding biomedical waste management. ${ }^{[18-20]}$ In contrast to the present study, several other studies showed good/adequate knowledge levels among nurses. ${ }^{[9,17,21]}$ Another study showed adequate knowledge among nursing students regarding biomedical waste management. ${ }^{[11]}$ Nursing student needs to improve their knowledge and translate it into their clinical practice.

Knowledge regarding color coding, disposal methods, universal precautions, and biomedical waste hazard symbols are crucial for the effective management of biomedical waste. In the present study, the majority of students were having poor knowledge levels regarding various domains of biomedical waste management namely awareness, color coding, biomedical waste disposal methods, and universal precautions, which was in contrast to other studies. ${ }^{[4,18]}$ Nursing students were having an excellent level of knowledge regarding biomedical hazard symbols, which is in line with other studies. ${ }^{[4,18]}$

Nursing students had an excellent attitude regarding biomedical waste management which is comparable to studies among nursing students. $[5,10]$ Studies conducted among nurses and health care workers also showed positive attitude ${ }^{[11,15}$, 17] while negative attitude was also shown 
among nurses. ${ }^{[3]}$ A study reported poor attitude among resident doctors regarding biomedical waste management in comparison to nursing staff.

The practices among nursing students regarding biomedical waste management were excellent which was in contrast with studies that showed poor pattern of practices among nurses and nursing students. $[10,16]$ Other studies conducted among nurses showed good level of practice among nurses which was in line with the present study.

In our study, about $40 \%$ of nursing students reported unsafe practices of recapping used needles which may expose them to needle stick injury. This was in contrast with a study that reported higher recapping practices among nurses.

Agonizingly, about $60 \%$ of nursing students had previous exposure to needle stick or sharps injury.

In our study, we found out that about one in three participants were not vaccinated against Hepatitis B (33.1\%) which is in line with another study that showed $20.7 \%$ of nurses were not vaccinated against Hepatitis B. ${ }^{[11]}$ In our study, one in five nursing students were not vaccinated against TT $(18.4 \%)$. So it should be made mandatory for all nursing students to get vaccinated against Hepatitis B and TT (every 5 years) before entering their clinical posting.

Several research evidences are available which suggest that biomedical waste management is widespread problem across countries. ${ }^{[22]}$ Some studies reported better knowledge but poor practices regarding biomedical waste management among nursing students when compared to nursing staff. ${ }^{[3,4]}$ Another study showed better biomedical waste management practices among medical students than nursing students.

Since biomedical waste management is part of the nursing curriculum, the findings of the study are staggering for nurse educators. It is a need of the hour for nursing students to be abreast with recent amendments in rules and policies regarding biomedical waste management as they will be future health care providers. Clear written guidelines and policies concerning biomedical management with regular enhancements should be made for nursing students.

This comprehensive study includes an adequate sample size. We are aware that there may be over-reporting of desirable responses due to self-report bias. Positive attitudes and good practices for biomedical waste management may be due to social desirability bias, but they may be weak. In future studies, health care workers from different centers with large sample sizes are warranted to explore the relationship between knowledge and practices regarding recent amendments in biomedical waste management rules. Regular teaching and training about recent amendments as well as newer safe and cost-effective scientific methods of waste management and periodic monitoring of practices regarding biomedical waste are highly recommended.

\section{CONCLUSION}

Although nursing student's attitudes and patterns of practice were excellent on the other hand they had an unsatisfactory level of knowledge related to recent amendments in biomedical waste management rules, 2019. Periodic assessment and regular teaching along with hands-on training programs with an emphasis on recent amendments in rules should be stressed to bridge the gap between knowledge, attitude, and practices.

\section{ACKNOWLEDGMENT}

The authors would like to acknowledge gratitude to all the nursing students who sincerely participated in the study without whom the study would never be completed.

\section{Conflict of Interest: None}

\section{Source of Funding: None}

Ethical Approval: Approved 


\section{REFERENCES}

1. Das NK, Prasad S, Jayaram K. A Tqm Approach To Implementation Of Handling And Management of Hospital Waste in Tata Main Hospital. Issued By Hospital Waste Management Committee. T.M.H. 2001;1112(1-2):75-8.

2. Park K. Hospital Waste Management. Park's Textbook of Preventive and Social Medicine. 25th Edition: Jabalpur, M/s Banarsidas Bhanot Publishers 2019; 849$54 \mathrm{p}$.

3. Sengodan VC, Amruth KH. Knowledge attitude and practice study on biomedical waste management among health care professionals and paramedical students in a Tertiary Care Government Hospital in South India. Int J Env Health Eng 2014;3:11.

4. Haider S, Kumari S, Kashyap V, Sunderam S, Singh SB. A study on knowledge and practice regarding biomedical waste management among staff nurses and nursing students of Rajendra Institute of Medical Sciences, Ranchi. Indian J Comm Health. 2015; 27, 1: 135-138.

5. Saini Jyoti, Choudhary Seema, Diksha, Kataria Pooja Awareness of Biomedical Waste Management among Nursing Students: A Hospital Based Study in Haryana. Indian J Prev. Soc. Med. 2020; 51 (1): 10-17.

6. "Bio-medical Waste Management Rules Amended to Protect Human Health": Dr. Harsh Vardhan [Internet]. [cited 2021 Jun 21]. Available from: https://pib.gov.in/Pressreleaseshare.aspx?PR ID $=1526326$

7. Dey P, Das B. Knowledge, attitude, and practices about biomedical waste management as per 2016 rules among resident doctors and nursing staff in a tertiary care specialty hospital: A crosssectional study. J Med Soc 2020;34:31-5.

8. Misra V, Pandey SD. Hazardous waste, impact on health and environment for development of better waste management strategies in future in India. Environ Int. 2005 Apr;31(3):417-31.

9. Chudasama RK, Rangoonwala M, Sheth A, Misra SKC, Kadri AM, Patel UV. Biomedical Waste Management: A study of knowledge, attitude and practice among health care personnel at tertiary care hospital in Rajkot. J Res Med Den Sci. 2013;1:17-22.
10. Kaur Najotra D, Slathia P, Raina S, Ghai S. Knowledge attitude and practices of biomedical waste management among medical and nursing students in a teaching hospital of J \& K, India. Indian J Microbiol Res 2020;7(1):20-23.

11. Soyam GC, Hiwarkar PA, Kawalkar UG, Soyam VC, Gupta VK. KAP study of biomedical waste management among health care workers in Delhi. Int J Community Med Public Health 2017;4:3332-7.

12. Anand P, Jain R, Dhyani A. Knowledge, attitude and practice of biomedical waste management among health care personnel in a teaching institution in Haryana, India. Int $\mathbf{J}$ Res Med Sci 2016;4:4246-50.

13. Kumar M, Ranjan PK, Singh P, Kumar R, Singh SN. Assessment of KAP Score for Biomedical Waste Management. Int $\mathbf{J}$ Health Clin Res. 2020 Dec 30;3(12):160-4.

14. Chaudhary A, Mahajan A. Level of understanding of revision of biomedical waste rules, 2016 among nursing students in Shimla, Himachal Pradesh. CHRISMED J Health Res 2018;5:127-32.

15. Mohamed HH, Abd El-Kader RG, Ibrahim AA-W. Knowledge, Attitude and Practice of Health Care Personnel about Medical Waste Management in Selected Family Health Centers in Mansoura, Egypt. Int J Innov Res Med Sci. 2019 Jun 13;4(06):349 to 356.

16. Kariwala P, Dixit AM, Jain PK, Rani V, Srivastava DK. Assessment of knowledge and skills of nursing staff working in a tertiary care hospital of Western Uttar Pradesh. Indian J Comm Health. 2018; 30, 1: 51-55.

17. Shyamala, R., and Naveen, G. 2016. A Cross Sectional Study on Health Care Waste Management among Health Care Personnel in a Tertiary Care Center, Kannur, Kerala, India. Int.J.Curr.Microbiol.App.Sci. 5(9): 340-345.

18. Pinto V, Joshi S, Velankar D, Mankar M, Bakshi H, Nalgundwar A, et al. A comparative study of knowledge and attitudes regarding biomedical waste (BMW) management with a preliminary intervention in an academic hospital. Int $\mathbf{J}$ Med Public Health. 2014;4(1):91-5.

19. Rajdev S, Mullan S. Assessment of knowledge, attitudes \& practices among doctors, Nurses \& ward aids on nosocomial infections in tertiary care hospital. Int J Med Microbiol Trop Dis 2019;5(4):222-225. 
Surya Kant Tiwari et.al. Knowledge, attitude and practices regarding biomedical waste management as per 2019 rules among nursing students.

20. A M, Eshwar B. Knowledge, Attitude and Practice of Biomedical waste management among health care personnel in a tertiary care hospital in Puducherry. Int $\mathbf{J}$ Biomed Res. 2015 Mar 31;6:172.

21. Lavanya K. M., Majhi P, Knowledge, Attitude and Practices (KAP) about biomedical waste management among hospital staff- A crossectional study in a tertiary care hospital, Andhra Pradesh, India. J Community Health Manag 2018;5(1):32-36

22. Shamnani G, Verma DK, Bhartiy SS. Knowledge, awareness, attitude, and practice regarding biomedical waste management among health care workers in tertiary care setting. Int $\mathbf{J}$ Med Sci Public Health 2018;7(8):611-615.

How to cite this article: Tiwari SK, Srivastava SP, Chauhan S. Knowledge, attitude and practices regarding biomedical waste management as per 2019 rules among nursing students. Int J Health Sci Res. 2021; 11(9): 41-48. DOI: https://doi.org/10.52403/ijhsr. 20210906 